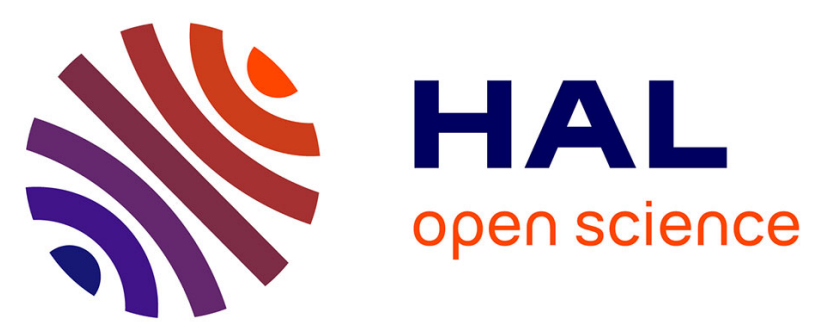

\title{
Venous stent in liver transplant candidates: Dodging the top tip traps
}

Aude Merdrignac, Heithem Jeddou, Pauline Houssel-Debry, Erwan Flecher, Michel Rayar, Karim Boudjema

\section{> To cite this version:}

Aude Merdrignac, Heithem Jeddou, Pauline Houssel-Debry, Erwan Flecher, Michel Rayar, et al.. Venous stent in liver transplant candidates: Dodging the top tip traps. Liver Transplantation, 2017, 23 (7), pp.972-975. 10.1002/lt.24748 . hal-01558817

\section{HAL Id: hal-01558817 https://hal-univ-rennes1.archives-ouvertes.fr/hal-01558817}

Submitted on 25 Aug 2017

HAL is a multi-disciplinary open access archive for the deposit and dissemination of scientific research documents, whether they are published or not. The documents may come from teaching and research institutions in France or abroad, or from public or private research centers.
L'archive ouverte pluridisciplinaire HAL, est destinée au dépôt et à la diffusion de documents scientifiques de niveau recherche, publiés ou non, émanant des établissements d'enseignement et de recherche français ou étrangers, des laboratoires publics ou privés. 


\section{Manuscript ID: LT-16-696}

\section{Venous stent in liver transplant candidates: dodging the top tip traps}

Merdrignac $A^{1,2,3}$, Jeddou $H^{1}$, Houssel-Debry $P^{4}$, Flecher $E^{3,5}$, Rayar $M^{1,3,6}$, Boudjema K $1,3,6$

(1)

${ }^{1}$ Service de Chirurgie Hépato-Biliaire et Digestive, CHU Pontchaillou, Rennes, France.

2 INSERM UMR991, CHU Pontchaillou, Rennes, France.

${ }^{3}$ Université de Rennes 1, Rennes, France.

${ }^{4}$ Service des maladies du foie, CHU Pontchaillou, Rennes, France.

${ }^{5}$ Service de Chirurgie Thoracique, Cardiaque et Vasculaire, CHU Pontchaillou, Rennes, France.

${ }^{6}$ INSERM CIC1414, CHU Pontchaillou, Rennes, France.

Corresponding author :

Dr Merdrignac Aude

Service de Chirurgie Hépato-Biliaire et Digestive

$\mathrm{CHU}$ Pontchaillou

2 rue Henri le Guilloux

35033 Rennes cedex

France

Phone : +33299284265

Fax : +33299284129

e-mail : aude.merdrignac@chu-rennes.fr

Letter from the frontline

Keywords : liver transplantation, transjugular intrahepatic portosystemic shunt, surgery

Financial support: none

Conflict of interest: none

Abbreviations:

CBP: cardiopulmonary bypass

CT: computed tomography

IVC: inferior vena cava

TIPS: transjugular intrahepatic portosystemic chunt 
To the Editor

Transjugular intrahepatic portosystemic shunt (TIPS) is an effective treatment for refractory ascites, upper gastrointestinal bleeding or hepatorenal syndrome in liver transplant candidates. ${ }^{(1)}$ Implantation of a TIPS before transplantation has been shown to improve grafts and patient survival ${ }^{(2)}$

Despite its safety, complications such as migration of the stent in the portal vein or the right atrium can occur in $30 \%$ of the patients. ${ }^{(2)}$ Implanting the liver graft over the top of the TIPS or a caval stent can also be challenging. We report two strategies to avoid intraoperative difficulties depending on the level of the stent upper tip.

\section{Case 1}

A 66-year-old woman suffering from alcoholic cirrhosis presented with refractory ascites and hydrothorax. After TIPS implantation, the patient developed antral ectasia and liver transplantation was indicated. Preoperative computed tomography (CT) scan showed that the TIPS top had slipped up to the junction of the right atrium and suprahepatic inferior vena cava (Fig. 1A).

On surgery, the TIPS was found incrusted in the sub-atrial vena cava wall and could not be removed without risk of tearing the intra-thoracic inferior vena cava (IVC).

Liver explantation was performed preserving the retrohepatic vena cava and temporary portocaval shunt was performed. The TIPS was stapled and cut at the end of the right hepatic vein and its upper portion left intact in the cava. The liver graft was implanted using the latero-lateral vena cava technique as described by Belghiti et al. ${ }^{(3)}$ Briefly, the recipient IVC was clamped laterally including the inferior tip of the remnant portion of the stent. The IVC was then opened longitudinally including the origin of the remnant portion of the TIPS (Fig. 1B).

Latero-lateral cavo-caval anastomosis was performed. The running suture included the stent and the wall of the vein. 
Heparin was administrated until day 7 , then coumadin. Control ultrasound at 1 month showed normal suprahepatic and caval flow.

\section{Case 2}

A 19-year-old woman with a previous pediatric history of thoraco-abdominal neuroblastoma had presented post-radiotherapy vena cava thrombosis since the age of 6 years. Percutaneous angioplasties and multiple stenting provided temporary hepatic and caval vein repermeabilization. However, IVC thrombosis recurred at the age of 13 years, leading to Budd Chiari syndrome and eventually irreversible liver failure indicating liver transplantation. Preoperative CT scan showed that the IVC stent was partially broken and had slipped into the right atrium with its top incrusted in the atrial wall underneath the tricuspid valve (Fig. 2A) and on the edge of the coronary sinus.

Due to the risk of atrial thrombosis and/or stent migration, it was decided to remove the intraatrial stent and for that, to perform liver transplantation combined with partial replacement of the right atrium.

Donor surgery consisted of "en bloc" harvesting of the liver and the heart (Fig. 3A). Recipient Surgery was performed through a combined sternotomy and right subcostal incision. The diaphragm was divided down to the central tendon. A cardiopulmonary bypass (CPB) was established between the ascending aorta, the superior vena cava and the right femoral vein.

The presence of azygo-lumbar collaterals allowed permanent ligation of the inferior vena cava above the renal vein implantations. Under CPB with moderate hypothermia $\left(32^{\circ} \mathrm{C}\right)$ and after administration of cold cardioplegia, the native liver was removed "en bloc" with the retrohepatic vena cava and the lower portion of the recipient right atrium, including the stent (Fig. 2B), with care not to injure the coronary sinus.

Liver implantation was performed using a partial right atrium patch of the donor. The atrioatrial anastomosis was performed preserving the coronary sinus (Fig. 3B) and the lower end of the donor cava was stapled. 
Portal, arterial and biliary anastomoses were conventional. During the postoperative course, ultrasound imaging and CT scan showed permeable suprahepatic veins and the inferior vena cava.
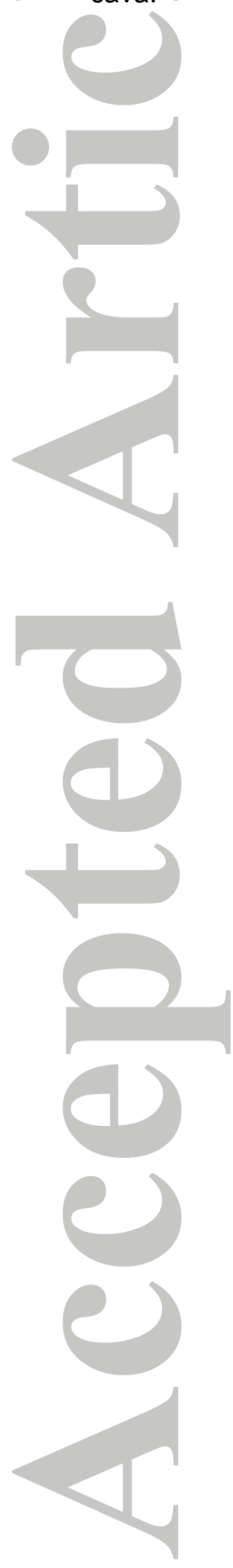


\section{Discussion}

In liver transplant candidates, the top of a preoperative TIPS or caval stent displacement can alter the feasibility of liver transplantation. Through these two reported cases, we showed that stent tops could be either left in place or removed. However, stent removal can lead to an unexpected life-threatening intraoperative event. ${ }^{(4)}$ Removal of the stent can require the use of CPB which can complicate the procedure and postoperative course.

Preoperative imaging is essential to identify misplaced or displaced stent. Surgical management of migrated stent during liver transplantation must be anticipated. Depending on the level of stent migration, intraoperative difficulties and risks can differ. Stent migration into the portal and superior mesenteric veins is the most common case. The embedded stent can be transected and the anastomosis performed directly over the stent to avoid hemorrhagic removal. ${ }^{(2)}$ Stent migration into the inferior suprahepatic vena cava and the right atrium is less frequent and can be more difficult to manage.

In the first case, the top of the stent located at the junction between the right atrium and inferior vena cava could be preserved and transected as previously described by Meyer. ${ }^{(5)}$ There is a high risk of injuring the atrium if removal of the stent is attempted. ${ }^{(4)}$ The remnant stent is well-tolerated and no secondary stenosis or thrombosis has been described.

In the second case, the risk of intra-atrial thrombosis was high with part of the broken stent left hooked in the atrial wall. Removal of the entire stent was therefore necessary. Temporary CPB allowed safe exploration of the right atrium. The difficulty remained in the conservation of the coronary sinus during the atriotomy and the anastomosis of the right atrium.

One should be aware of stent top migration before liver transplantation. Different strategies exist to bypass difficulties during caval anastomosis and enable a safe procedure depending on the level of stent top migration.

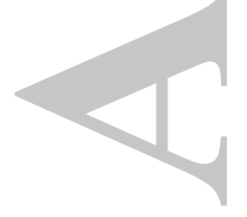




\section{Bibliography}

1. Patidar KR, Sydnor M, Sanyal AJ. Transjugular portosystemic shunt. Clin Liver Dis 2014;18:853.

2. Guerrini GP, Pleguezuelo M, Maimone S, Calvaruso V, Xirouchakis E, Patch D, et al. Impact of Tips Preliver Transplantation for the Outcome Posttransplantation. Am J Transplant 2009;9:192 $\square 200$.

3. Belghiti J, Noun R, Sauvanet A. Temporary portocaval anastomosis with preservation of caval flow during orthotopic liver transplantation. Am J Surg 1995;169:277 $\square 9$.

4. Tivener D, Vannucci A, Fagley RE, Doyle M, Shenoy S, Chapman W, et al. Atrial Laceration Caused by Removal of a Transjugular Intrahepatic Portosystemic Shunt Necessitates Emergent Cardiopulmonary Bypass during Liver Transplant: A Case Report. Transplant Proc 2011;43:2810 $\square$ 3.

5. Meyer C, Odeh M, Herrera JJ, Resende A, Perarnau J-M, Ellero B, et al. Orthotopic liver transplantation with a suprahepatic vena caval anastomosis over a transjugular intrahepatic portosystemic shunt. J Am Coll Surg 1998;187:217 $\square 187$ :

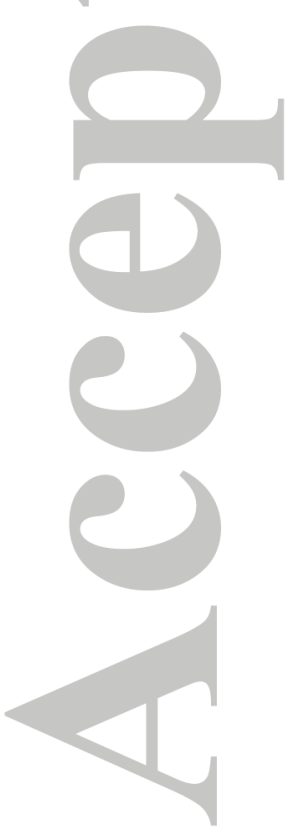




\section{Figure legends}

Figure 1: Case 1. A) Preoperative CT scan. B) Intraoperative view showing the remnant portion of the TIPS (white arrow) in the inferior vena cava (IVC). The remnant portion of the TIPS was left incrusted in the stump of the right hepatic vein and its intraluminal wall was opened longitudinally over $1 \mathrm{~cm}$. HA: hepatic artery.

Figure 2: Case 2. A) Preoperative CT scan showing the broken stent in the right atrium (white arrow). B) After cardiopulmonary bypass was established, the recipient right atrium (RA) was opened showing the broken incrusted stent tip (white arrow). D: diaphragm. IVC: inferior vena cava.

Figure 3: Case 2. A) En-bloc heart-liver graft. The right atrium is ready to be removed from the heart and kept attached to the inferior vena cava. B) Intraoperative view showing the atrio-atrial anastomosis. The forceps shows the coronary sinus. RRA: recipient right atrium, DRA: donor right atrium.

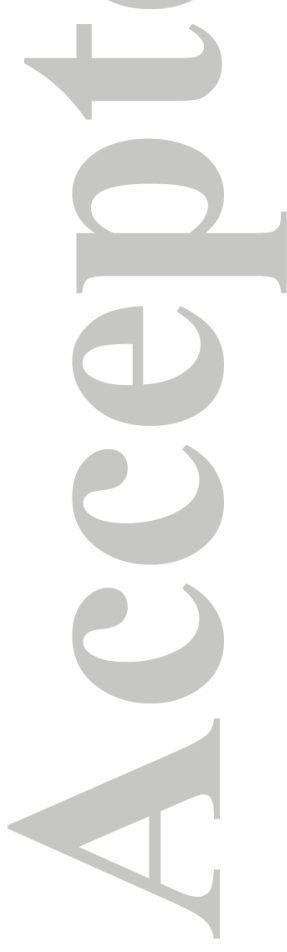




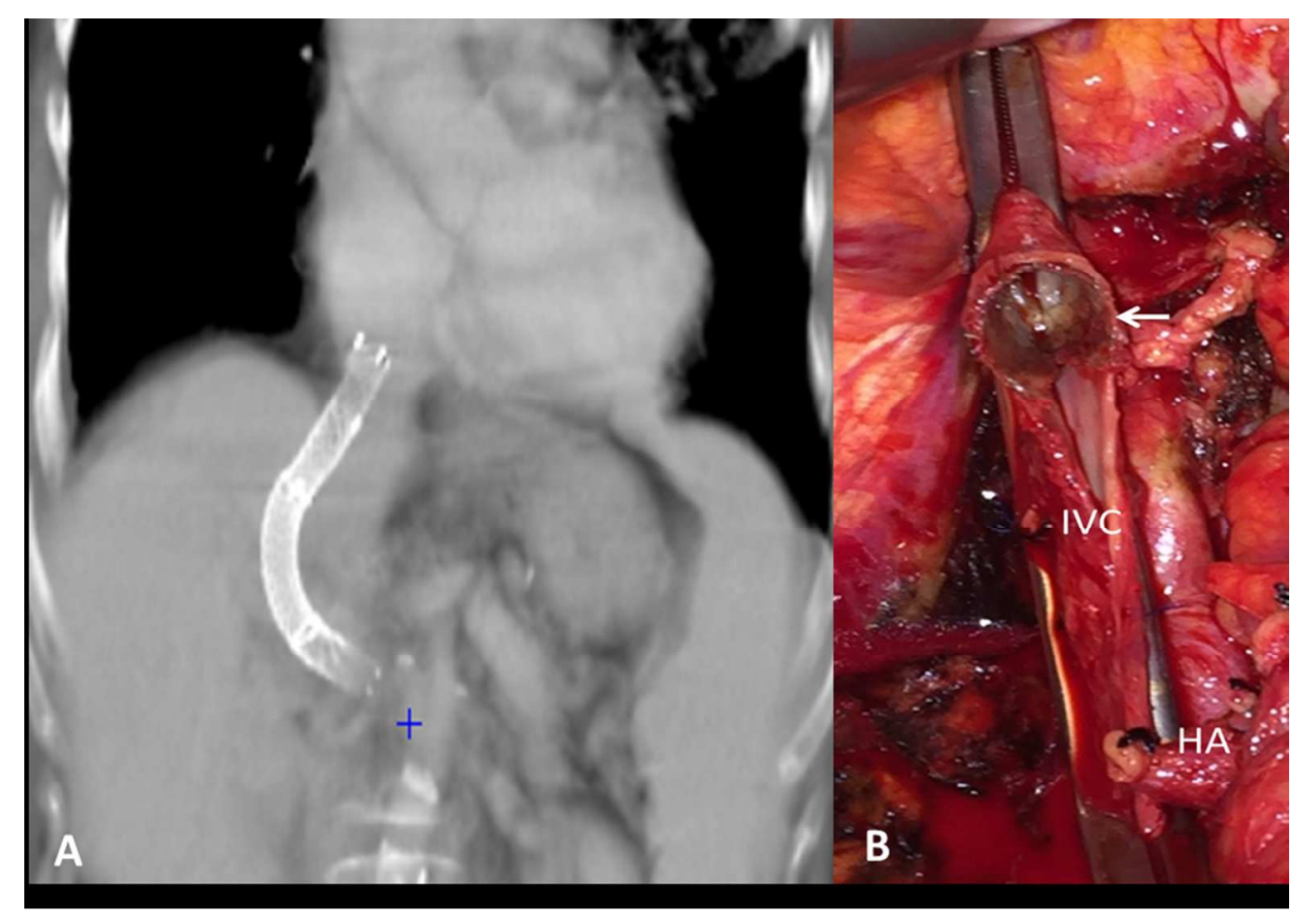

$84 \times 59 \mathrm{~mm}(300 \times 300$ DPI $)$

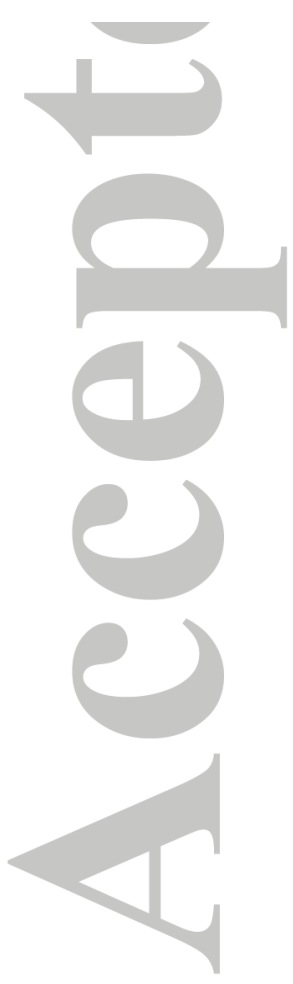



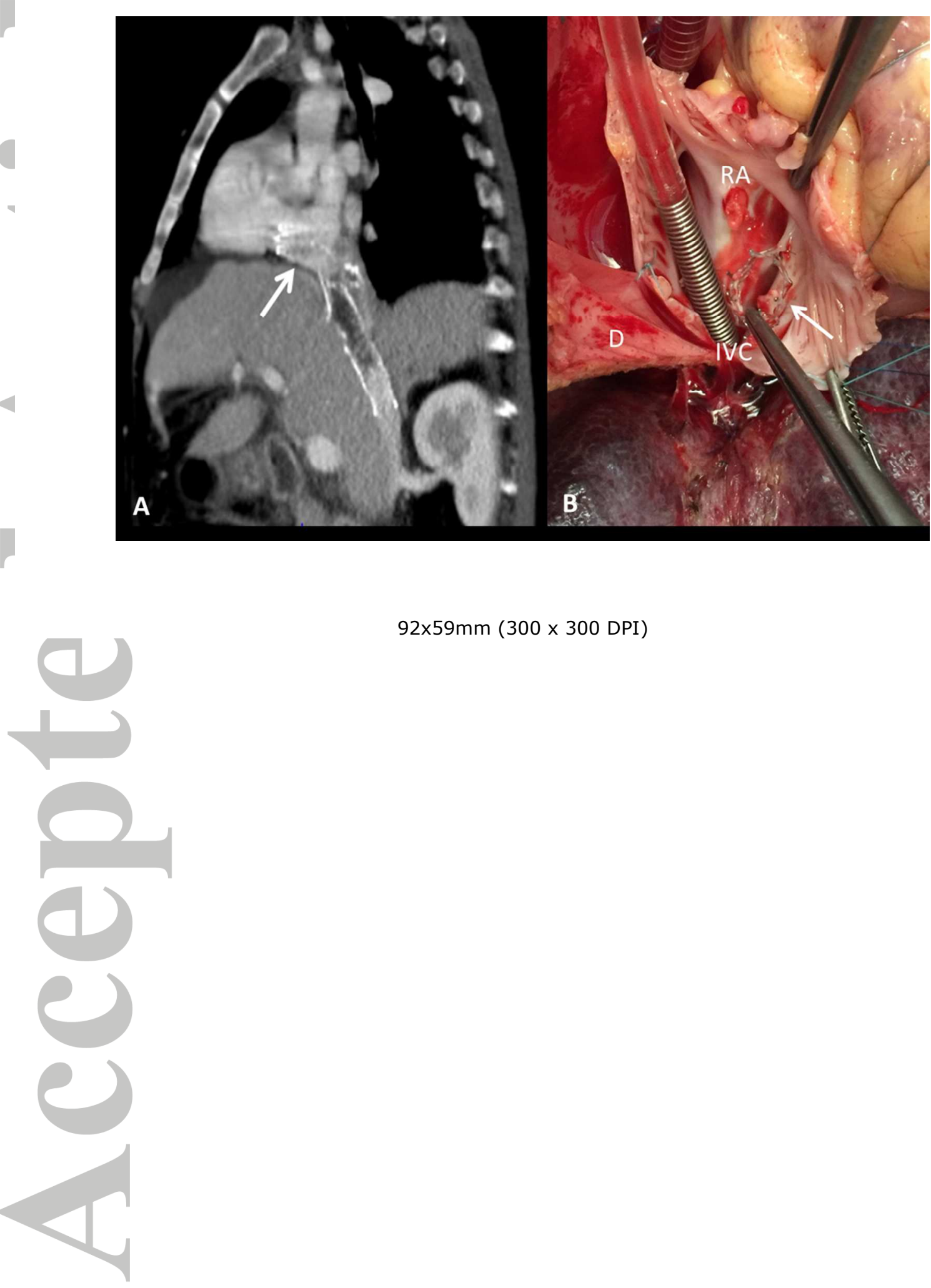

$92 \times 59 \mathrm{~mm}(300 \times 300$ DPI $)$ 


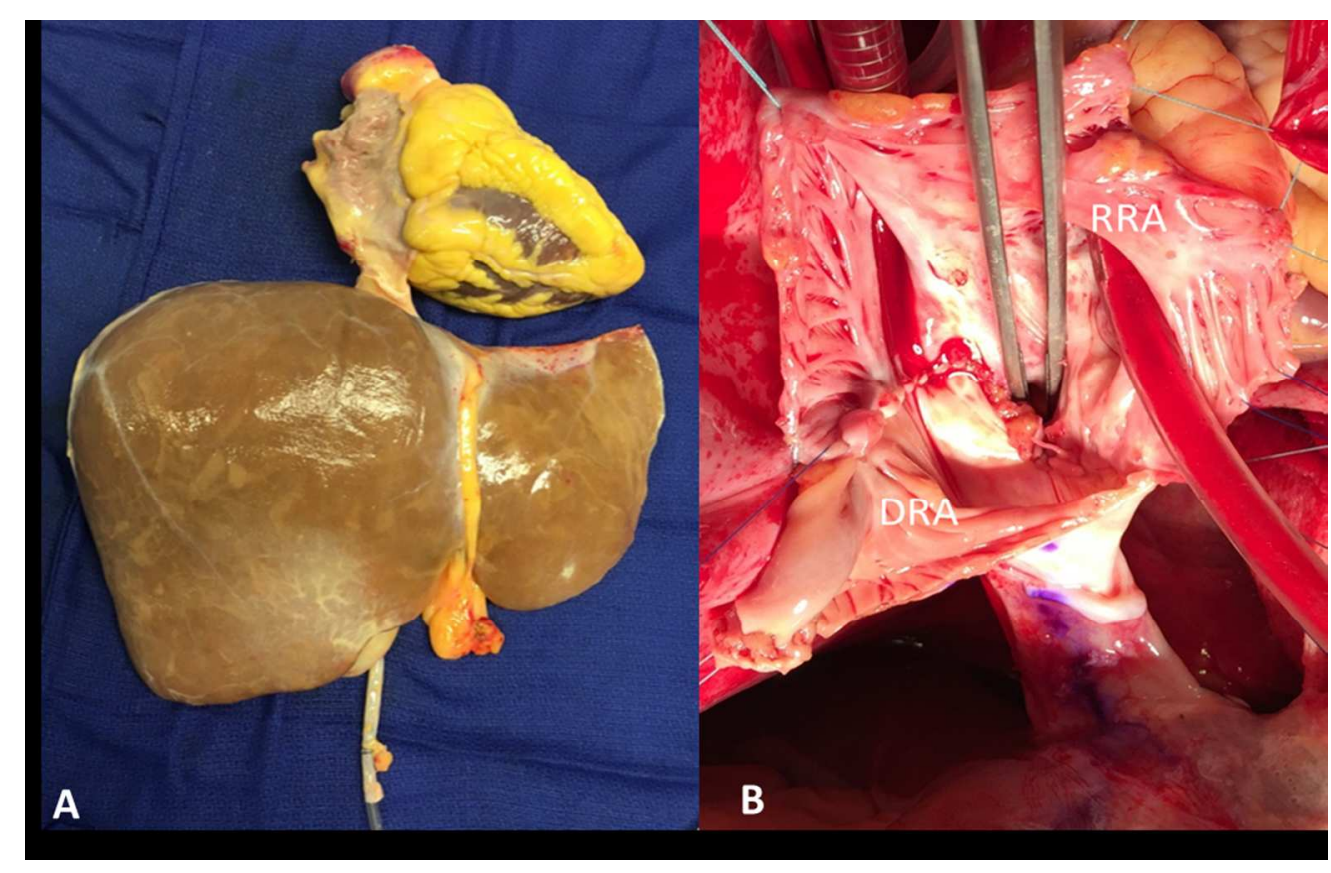

$92 \times 59 \mathrm{~mm}(300 \times 300$ DPI $)$

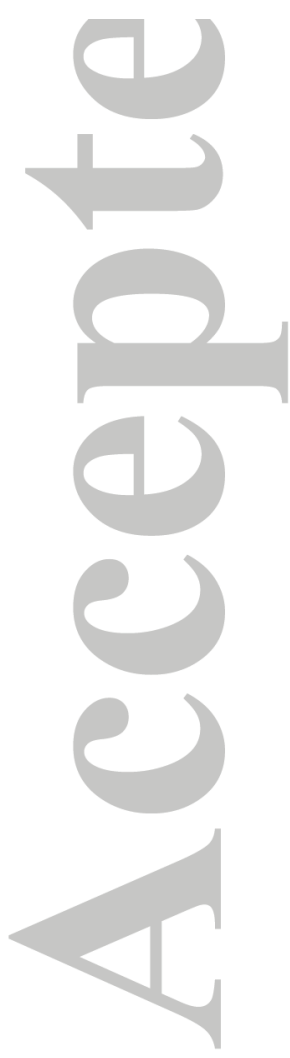

